\title{
Familial hypocalciuric hypercalcemia
}

INSERM

\section{Source}

INSERM. (1999). Orphanet: an online rare disease and orphan drug data base. Familial hypocalciuric hypercalcemia. ORPHA:405

Familial hypocalciuric hypercalcemia $(\mathrm{FHH})$ is a generally asymptomatic genetic disorder of phosphocalcic metabolism characterized by lifelong moderate hypercalcemia along with normo- or hypocalciuria and elevated plasma parathyroid hormone (PTH) concentration. 